\title{
Propulsion Shaft and Gearbox Failure in Marine Vessels: A Duration Model Analysis
}

\author{
D. E. Onwuegbuchunam ${ }^{1 *}$, I. C. Ogwude², C. C. Igboanusi², K. O. Okeke ${ }^{1}$, N. N. Azian ${ }^{3}$ \\ ${ }^{1}$ Department of Maritime Management Technology, Federal University of Technology, Owerri, Nigeria \\ ${ }^{2}$ Department of Transport Management Technology, Federal University of Technology, Owerri, Nigeria \\ ${ }^{3}$ Strauz Marine \& Engineering Ltd., Federal Ocean Terminal (FOT), Onne, Nigeria \\ Email: ^don@futo.edu.ng
}

How to cite this paper: Onwuegbuchunam, D.E., Ogwude, I.C., Igboanusi, C.C., Okeke, K.O. and Azian, N.N. (2020) Propulsion Shaft and Gearbox Failure in Marine Vessels: A Duration Model Analysis. Journal of Transportation Technologies, 10, 291-305. https://doi.org/10.4236/jtts.2020.104019

Received: June 11, 2020

Accepted: August 7, 2020

Published: August 10, 2020

Copyright (c) 2020 by author(s) and Scientific Research Publishing Inc. This work is licensed under the Creative Commons Attribution International License (CC BY 4.0).

http://creativecommons.org/licenses/by/4.0/

\begin{abstract}
The need to mitigate downtime in marine vessels arising from propulsion system failures has led ship operating companies to devote enormous resources for research based solutions. This paper applied duration models to determine failure probabilities of shaft and gearbox systems in service boats. Using dockyard's event history data on boat repairs and maintenance, we applied Kaplan Meier hazard and survival curves to analyse probability of failure of shaft and gearbox systems in supply, crew and tug boats. We found that average time to shaft and gearbox failure was 8.33, 5.23 and 5.21 months for tug, supply and crew boats respectively. The hazard plots however, showed that supply boats had higher probability of failure than crew boats and then tug boats in that order. Further analysis using Cox regression model showed that the boats' shaft and gearbox system failures were significantly affected by level of lubrication oil, stress corrosion cracking and impacts on the propulsion system's components. The paper proposes that design of maintenance schedules for service boats should take the following into consideration: 1) estimated survival limits or failure times of propulsion system's shaft and gearboxes, 2) significant risk factors that affect failure mode of the propulsion system components.
\end{abstract}

\section{Keywords}

Shaft and Gearbox Failure, Propulsion System, Hazard Rates, Survival Analysis, Service Boats

\section{Introduction}

The productivity of service vessels depends on good working condition of propulsion system-consisting of main engine, gearbox reduction system, propeller, 
propulsion shaft and bearings. Specifically, properly aligned propulsion shaft and sound gearbox systems are critical to maintaining smooth operation of a vessel's propulsion system. Shaft and gearbox failure in propulsion system could occur at all stages of a vessel's lifecycle and which event often impact seriously on the manoeuvrability and safety of the vessel. In addition, propulsion system component failures could lead to expensive loss of hire and disruption in vessel's schedule of operation. Apart from commercial losses, environmental impact after an accident as a result of propulsion system failure is another concern that is becoming increasingly important and subject to inquiries from regulatory agencies and other stakeholders in the shipping industry. The factors responsible for gearbox failure and shaft misalignment in marine propulsion systems are random events. That is to say that system failure can occur without warning or opportunity for correction by operators. Consequently, various techniques have had to be developed to enable risk assessment of marine propulsion systems components and thus control downtime of vessels or their components. This paper seeks to develop a method for controlling shaft and gearbox failures in marine propulsion system using data from dockyard records.

\section{Objectives of Study}

The main objective of this study is to conduct event history analysis of shaft and gearbox systems in service boats.

The specific objectives of this study are to:

1) Estimate probability of failures in propulsion shaft and gearbox systems of service boats.

2) Compare the frequency of shaft and gearbox system failures in crew, tug and supply boats.

3) Determine significant causes of failure in shaft and gearbox systems of the boats.

This paper will be limited to analysis of failure events of shaft and gearbox systems in service boats (namely: crew, tug and supply boats).

\section{Conceptual Reviews}

\subsection{Configuration of Propeller Shaft and Gearbox Systems}

Propulsion systems take numerous forms depending on the size and purpose of a vessel. Figure 1 shows a typical single-shaft configuration from the output of the reduction gear to the propeller, including bearing locations. This configuration represents a medium-sized container vessel, which usually requires its engine revolutions per minute (rpm) to be reduced to a usable speed via a reduction gear/gearbox.

However, large oil tankers often have their large slow speed marine diesel engine directly coupled to the propulsion shaft, see Figure 2. Proper shaft alignment is extremely critical for these vessels since unusual bending moments or shear forces are directly transferred to the aft engine bearings. 


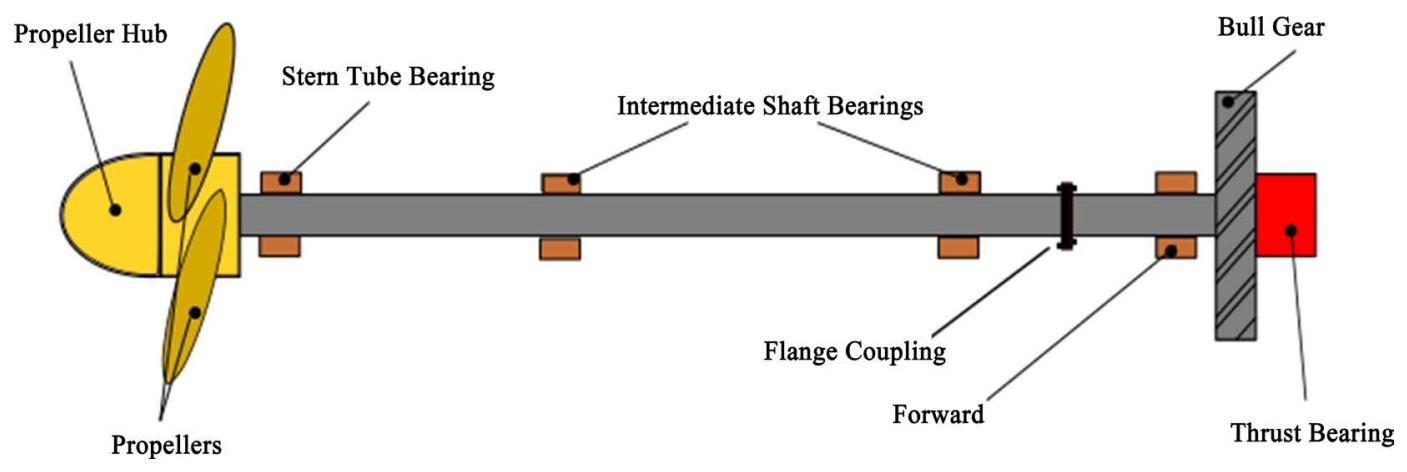

Figure 1. Components of a multi-section shaft coupled to a reduction gear.

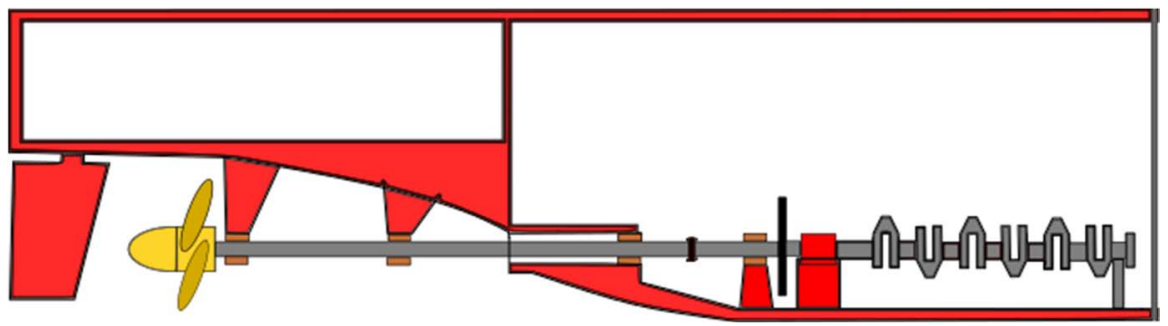

Figure 2. A directly coupled shaft/engine arrangement.

Smaller vessels may have multiple engines and shafts. If multiple shafts are used, then the stern tube bearing is moved forward and struts are used to support the shaft so that the propeller can be moved to a usable location without creating a non-hydrodynamic hull shape. Shaft alignment is defined by the American Bureau of Shipping (ABS) as a static condition observed at the bearings supporting the propulsion shafts [1]. According to ABS, risk of shaft misalignment could be avoided if care is taken to ensure that design criteria regarding certain parameters are maintained. These are namely: bearing vertical offsets, bearing reactions, bearing and crankshaft's positioning. Others are: gear alignment, shaft and bearings, coupling bolts, engine bedplate.

\subsection{Review of Empirical Literature}

Generally, risk in marine propulsion systems may arise from equipment failure, human error, external events and institutional error. Equipment failure-the most readily recognised hazard on ships may be categorized as either independent failure, such as loss of steering due to failure of a power pump or common cause failure, such as loss of propulsion and steering resulting from total loss of electrical power to the ship, etc. Risk from external events arises from hazards such as collision with other ships, sea state, wind and ice or other weather factors. Humans provide another source of risk to marine systems when they lack skill, are excessively fatigued, or commit sabotage. Institutional failure creates risks from poor management including inadequate training, poor communication and low morale [2]. Various models have been developed for risk assessment of marine propulsion systems components and thus to control downtime of vessels or their components. Essentially, these techniques fall into two catego- 
ries: quantitative and qualitative risk analysis. Notable ones according to Ayyub et al., [2] include: Safety and Review Audits, Checklist, What-if Analysis, Hazard Operability Analysis (HAZOP), Probabilistic Risk Analysis(PRA), and Probability Hazard Analysis (PrHA), etc. For example, Tran, Nguyen, Ma, Doan, and Vo. [3] assessed marine propulsion system reliability using Fault Tree model to identify main propulsion system parts with high failure criticality (main events) and other parts which failure in whole or in parts can lead to failure of main events. Their findings are also consistent with [4]. Ashraf [5] estimated statistical distribution of demand data on spare-parts in car maintenance stations. The object was to find theoretical distribution which approximates empirical failure time distribution of the auto parts. Guan [6] however, applied predictive analytics model to examine the relationship between Exhaust Gas Temperature (EGT) of ship main engine, engine load and hours of operation. The object was to obtain threshold value of EGT above which main propulsion engine may breakdown. Aksuand Turan [7] assessed the reliability of fixed and rotating Pod marine propulsion system units using combined models of Failure Mode and Effect Analysis (FMEA), Fault Tree Analysis (FTA) and Markov Analysis, to determine the reliability of the entire pod system. Important findings of their research are as follows: That the reliability of one rotating-pod unit was $98.8 \%$ for $1500 \mathrm{hrs}$ operation time and this gradually reduced to $80 \%$ for the operation time of $10,000 \mathrm{hrs}$. However, the reliability of the fixed-pod unit was $95.9 \%$ at the associated time.

Others papers on fault detection techniques were based on spectral content analysis of emitted vibration signals from rotating marine propulsion machinery. Signal processing is based on Fast Fourier Transform (FFT). The FFT converts a signal from the time domain to the frequency domain. The use of FFT also allows its spectral representation [8]. Each frequency range is framed into a particular failure state. It is very useful when periodic patterns are searched [9]. Vibration analysis also provides information about fault's origin and/or its severity. Specifically, Zhang [10] applied order-bispectrum method to detect gearbox crack faults during speed-up process. Consistent with Zhang [10], Yue and Zue [11] also assessed faults in gearbox mechanism using the calculated order tracking method. Hongxia and Liming [12] applied an extension of vibration signal processing using time series auto-regressive models and Empirical Mode Decomposition (EMD). Li, Yan, Yuan, Zhao and Peng [13] employed the technique of bispetrum analysis augmented with Artificial Neural Network (ANN) model to analyse faults in gearbox systems using data obtained from gearbox simulation. Their findings show that bispectral patterns of varying gear fault severities are such that distinct fault features of the vibration signals of a marine gearbox can be extracted effectively using the bispectrum. Wave length filtering methods can also be applied to model fault diagnosis. For example, Lin and Zuo [14] applied an adaptive wavelet filter based on Morlet wavelet to detect symptoms from vibration signals of a gearbox with early fatigue tooth crack. Sharma and Vishwakarma [15] modelled a feeding system of sugar industry as a timehomogenous Markov's operative process. In their paper, the reliability and avail- 
ability function of the feed system were assessed through the development of a mathematical optimization model of steady state availability showing constant failure and repair rates of system components. Using Genetic Algorithm (GA) and system design decision model, optimal system parameters were identified and this enabled the development of a system maintenance model.

The above studies applied fault prediction and detection models that were based on probability models and signal processing. It was also demonstrated that marine propulsion system failure is a random phenomenon, always associated with the operating state of the system which causes are either deterioration in the components of the system and/or human associated errors. Therefore the main concern should be to maintain system performance measures such as reliability and availability to achieve high profit goals and productivity [15]. Thus, continuous development of empirical models to analyse the behaviour of systems and establish their reliability, availability and maintainability are of great importance. The present paper contributes by building on failure mode prediction model (in this case; survival/hazard models) to analyse failure mode in service boats and the associated risk factors.

\section{Research Methodology}

\subsection{The Data}

The data in the study were obtained from records of a commercial dockyard and covered maintenance and repair activities carried out on service boats that called for service at the dock. The Dockyard which has a floating dock, specialised in repairs and maintenance of propulsion shaft and gearbox systems. The boats in the study which comprise crew, supply and tug boats were deployed as support vessels to oil \& gas activities in Nigeria's offshore oil fields. Details of their operations included transport of personnel, oil-rig equipment, towing services, ship's berthing and manoeuvring operations. The records contained details of ship-visits for routine maintenance or repairs following breakdowns. Thus, there were two categories of boats involved: the first category comprised of boats that were brought to the dockyard as a result of misaligned shaft or malfunctioned gearbox. The second category represented boats that were brought to the dock for routine maintenance and not as a result of failed propulsion system components. Information obtained from the skippers contacted showed that these vessels were kept on tight work schedules. In most cases, they were operated in excess of eight hours daily and maintenance policy was not strictly followed. However, the data compiled contained only vessels that had made repeated visits to the yard for a period of two years. Other details included frequency of ship-visits/tows to the yard for repairs, type of service boats involved, type of propulsion system's failure, cause of failure, dates the boats called at dock for service (repairs/maintenance) and time boats sailed after service at the dock. From the records, we obtained time lapse between successive visits made by the boats for service at the dock. In cases involving propulsion system failure, this time lapse was taken as a measure of time to event occurrence. Given the nature and level of disaggregation of the 
data collected; it was possible to address the main research questions using event history data modelling technique.

\subsection{Models for Event History Data Analysis}

Models to analyse time to occurrence of events are known variously as hazards models, duration models, Cox regression models, survival models, event history models and failure time models [16] [17]. The dependent variable in a hazards model consists of two parts: An event indicator (e.g., a binary indicator of whether ship propulsion system component failed) and a measure of time from baseline to the event or censoring. Censoring occurs when the event under study (gearbox or propulsion shaft failure) is not observed for a given period. Survival analysis is used to analyse data in which the time until the event (propulsion system failure) is of interest. The response is often referred to as a failure time, survival time, or event time.

Mathematically,

If $T$ denotes the response variable i.e. time before propulsion system failure, $T \geq 0$.

The survival function is:

$$
S(t)=\operatorname{Pr}(T>t)=1-F(t)
$$

The survival function in this case, gives the probability that a gearbox or propulsion shaft will survive past time $t$. As $t$ ranges from 0 to 1 , the survival function has the following properties:

It is non-increasing.

At time $t=0, S(t)=1$. In other words, the probability of surviving past time 0 is 1 .

At time $t=1, S(t)=S(1)=0$. As time goes to infinity, the survival curve goes to 0 .

In theory, the survival function is smooth. In practice, we observe events on a discrete time scale (days, weeks, months etc.). The hazard function $h(t)$, or rate is the instantaneous rate at which events occur, given no previous events.

$$
h(t)=\lim _{\Delta t \rightarrow 0} \frac{\operatorname{Pr}(t<T \leq t+\Delta t \mid T>t)}{\Delta t}=\frac{f(t)}{s(t)}
$$

The cumulative hazard describes the accumulated risk up to time $t$, $H(t)=\int_{0}^{t} h(u) \mathrm{d} u$.

If we know any one of the functions $S(t), H(t)$ or $h(t)$, we can derive the other two functions.

$$
\begin{gathered}
h(t)=-\frac{\partial \log (S(t))}{\partial t} \\
H(t)=-\log (S(t)) \\
S(t)=\exp (-H(t))
\end{gathered}
$$




\subsubsection{Kaplan-Meier Estimator}

The Kaplan-Meier (KM) survival curve is defined as the probability of surviving in a given length of time while considering time in many small intervals [18] cited in [19]. The Kaplan-Meier method can be used to estimate this curve from the observed survival times without the assumption of the underlying probability distribution [20].

Let $t_{1}<t_{2}<\cdots<t_{b}$ denote the ordered event times in the sample. For $t_{i}$, let $d_{i}$ denote the total number of failures occurring at time $t_{i}, s_{i}$ denotes the total number that have not failed by time $t_{i}, n_{i}$ denotes the total number at risk at time $t_{i}$, and $d_{i}=n_{i}-s_{i}$. Thus, Gokovali, Bahar \& Kozak [20] estimate of survival time $S(t)$ is given by:

$$
\hat{S}_{K M}(t)=\prod_{i: t_{i} \leq t}\left(1-\frac{d_{i}}{n_{i}}\right)=\prod_{i: t_{i} \leq t}\left(\frac{s_{i}}{n_{i}}\right)
$$

and the Greenwood's formula for standard error estimate of the KM estimator is given by:

$$
\widehat{S E}_{G}\left\{\hat{S}_{K M}(t)\right\}=\hat{S}_{K M}(t) \sqrt{\sum_{i: t_{t} \leq t} \frac{d_{i}}{n_{i} S_{i}}}
$$

\subsubsection{Cox Proportional Hazard Model}

The proportional hazards model otherwise known as Cox regression model according to Kaplan and Meier [21] (cited in [19]) is a statistical technique for exploring the association between for example, the survival time of a machinery component and the several explanatory covariates. Cox method does not assume any particular distribution for survival times, rather it assumes that the effect of different explanatory variables on survival times are constant over time and are additive in a particular way.

The hazard is modelled as:

$$
h(t / x)=h_{o}(t) \exp \left(\beta_{1} x_{1}+\beta_{2} x_{2}+\cdots+\beta_{n} x_{n}\right)
$$

where $x_{1}, \cdots, x_{n}$ are explanatory variables,

$h_{0}(t)$ : baseline hazard time $t$ representing the hazard for a boat's gearbox/shaft status with value 0 for all explanatory variables.

$\beta_{1}, \cdots, \beta_{n}$ : regression coefficients describing the impact of the covariates, which is estimated by the partial likelihood estimation procedure.

Parameter estimates in Cox model are obtained by maximizing the partial likelihood function for the observed data simultaneously with respect to $h_{0}(t)$ and $\beta$ as proposed by Cox [22].

\section{Data Presentation and Analysis}

In Table 1, we observe that there was a total of two hundred and ninety-nine boat-visits made to the dockyard. Out of this number, fourty nine represented visits made for maintenance of shaft and gearbox while the remaining counts represented that made for purpose of carrying out repairs following the component's failure. The latter can be interpreted as shaft/gearbox system's failure fre- 
quency. Considering the study period, the relatively low frequency of ship-visits to the dockyard for maintenance purposes observed in Table 1, suggests that regular boat maintenance schedule was not adhered to by the skippers. Based on these statistics, the failure or hazard rates and survival probabilities were calculated and plotted to obtain clearer insights into the data set.

Table 2 shows the distribution of event times (mean values) when shaft or gearbox (or both) component failed. Based on the table, we find that average time to component failure was $8.33,5.23$ and 5.21 months for tug, supply and crew boats respectively. The zero values represent censored observation denoting situations when there was no failure observed for the propulsion components.

As shown in Figure 3 which is based on extracts from Table 1, we observe that all categories of the service boats experienced propulsion system's component failure to some degree. However, this was more pronounced in supply and crew boats. The figure demonstrates that failures involving separately shafts and gearboxes were more prevalent in supply and crew boats. This outcome is understandable given that supply boats are usually employed to evacuate heavier loads and subjected to more hours of operation moving from one offshore location to another during their operation. In a similar vein, crew boats would have (in our expectation) been similarly operated, thus rendering their gearbox and propeller shaft system more susceptible to failures. However, tug boats in practice, are usually engaged in ancillary/support services and may be less subject to wear and tear in comparison to the others. This argument may explain the low casualty observed.

Table 1. Frequency of ship visits to the dockyard and purpose.

\begin{tabular}{ccccc}
\hline & \multicolumn{4}{c}{ Type of vessel } \\
\cline { 2 - 4 } Purpose of visit & tug & supply & crew & Total \\
\hline Shaft failure & 17 & 89 & 35 & 141 \\
Gearbox failure & 7 & 52 & 14 & 73 \\
Shaft/gearbox failure & 5 & 21 & 10 & 36 \\
Maintenance & 5 & 32 & 12 & 49 \\
Total & 34 & 194 & 71 & 299 \\
\hline
\end{tabular}

Source: Author, field work.

Table 2. Average time to event (shaft/gearbox failure or censored).

\begin{tabular}{cccc}
\hline & & & Time (months) \\
\cline { 3 - 3 } Boat type & Status & No. of boats & Mean \\
\hline Tug & 0 & 5 & 5.347 \\
Supply & 1 & 29 & 8.326 \\
\hline Crew & 0 & 32 & 5.126 \\
& 1 & 162 & 5.229 \\
\hline
\end{tabular}

Source: Authors, data analysis (based on dockyard records). 1: failed, 0: censored. 


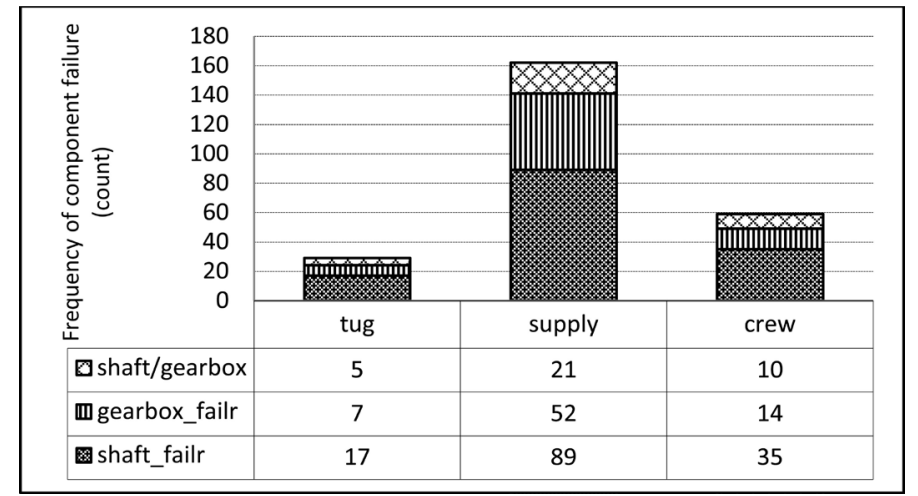

Source: author.

Figure 3. Distribution of type of propulsion system failure by type of vessel.

Other frequency distributions of data on factors affecting shaft and gearbox failure in service boats are listed in Appendix 3 and Appendix 4. These factors (which are dummy variables taking on values of 1 or 0 ) were used as explanatory variables in Cox regression analysis. The censor variable (see Appendix 1) is also a dummy with a value of 1 indicating shaft/gearbox failure and value 0 if censored.

Figure 4(a) represents Kaplan Meier curve showing hazard or failure rates of gearbox/shaft components of the boats under study. By inspection, we observe a decreasing horizontal curve between points 0 and 24 month mark on time axis. Since the curve lies below 0.25 mark on probability axis, it implies that shaft and gearbox in crew boats have near 0 probability of failure. However, beyond this interval, the hazard rate spikes above the 0.25 probability range. Conversely, a look at the survival curve in Figure 4(b) shows that the same system components have survival probabilities which range from 0.90 to 0.50 within 24-month point on time axis. Details from the two figures suggest that in crew boats, the likelihood of propulsion shaft and gearbox failure is minimal over a period of 24 months. In the subsequent sections, the terms system components and propulsion components were used interchangeable to refer to shaft and gearbox.

In Figure 5(a), we observe a different scenario in supply boats where probability of propulsion system failure remained below 0.25 within 0 to 16 months (in between repairs) but continued on a steady rise afterwards. The converse is also true (see Figure 5(b)) as survival probabilities associated with the propulsion systems drops from approximately 0.90 to zero within 18 months. By comparison, components failure is more likely (increased at $16^{\text {th }}$ month) in supply boats than in crew boats.

For tug boats, the probability of failure of propulsion components followed a similar pattern as in crew boats. As shown in Figure 6(a), this probability was minimal (below 0.25 ) in the first 18 months (in between repairs). However, we note a steady increment in hazard rates after the 18 month interval. This outcome is consistent with the survival curve in Figure 6(b), which shows that probability of component's survival dropped from 0.90 to 0 at $26^{\text {th }}$ month point on the time axis. In other words, after $18^{\text {th }}$ month (in between repairs) survival probabilities drop to zero. 

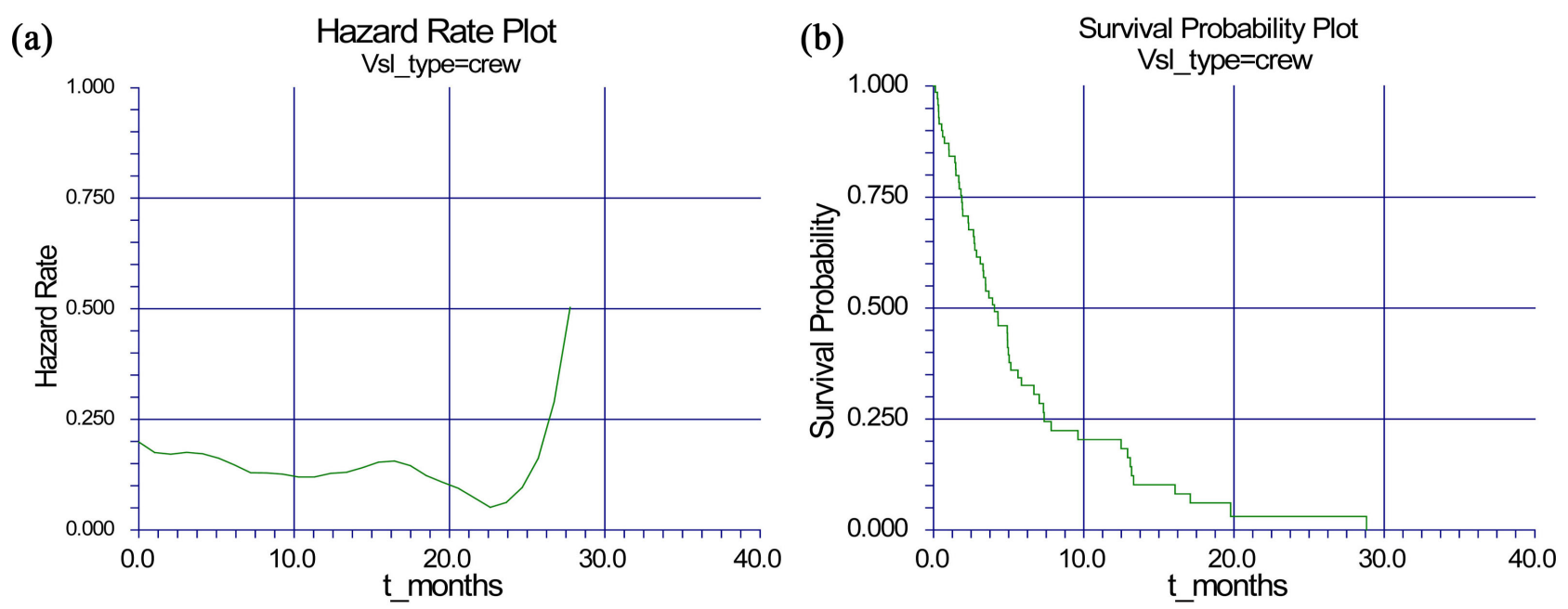

Figure 4. Kaplan Meier hazard/Survival curves for failure/survival times of shaft/gearbox system in crew boats.

(a)

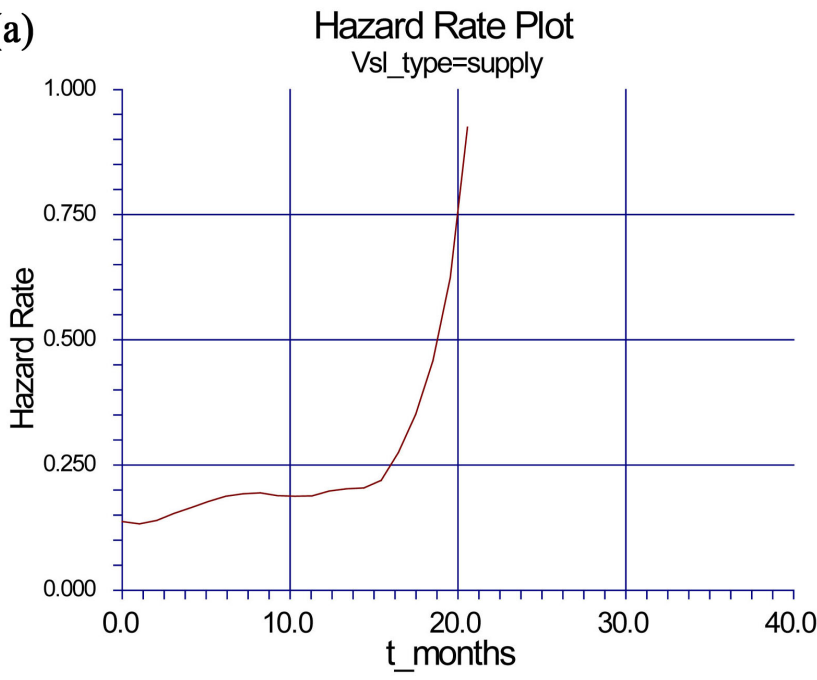

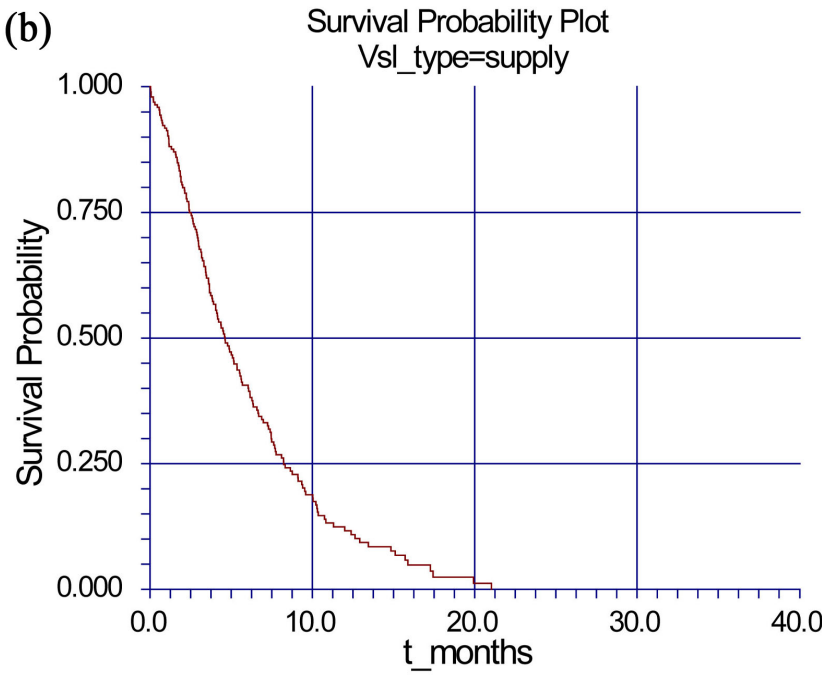

Figure 5. Kaplan Meier hazard/Survival curves for failure/survival times of shaft/gearbox system in supply boats.

(a)

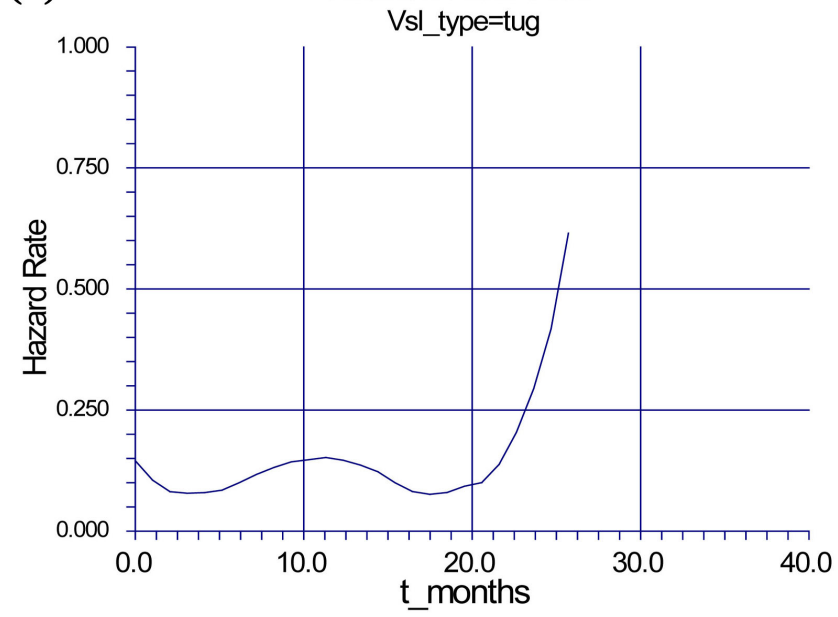

(b)

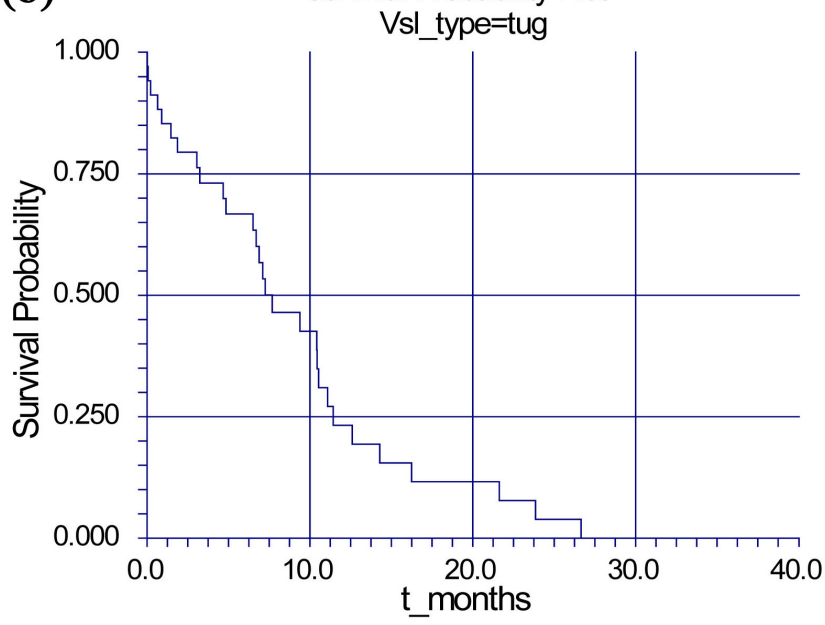

Figure 6. Kaplan Meier hazard/Survival curves for failure/survival times of shaft/gearbox system in tug boats. 
From the foregoing, it was observed that shaft and gearbox systems endurance showed a similar pattern in crew and tug boats. However, Figure 7 shows that in the long run (beyond 10 month point on time axis) the propulsion system components endure more in tug boats than in crew boats. It is also evident in Figure 7 that propulsion components were more likely to fail in supply boats, followed by crew boats and lastly tug boats. However, it was necessary to ascertain risk factors that could lead to the observed failures. The Cox regression result output in Table 3 shows the significant factors affecting shaft and gearbox failure in the service boats.

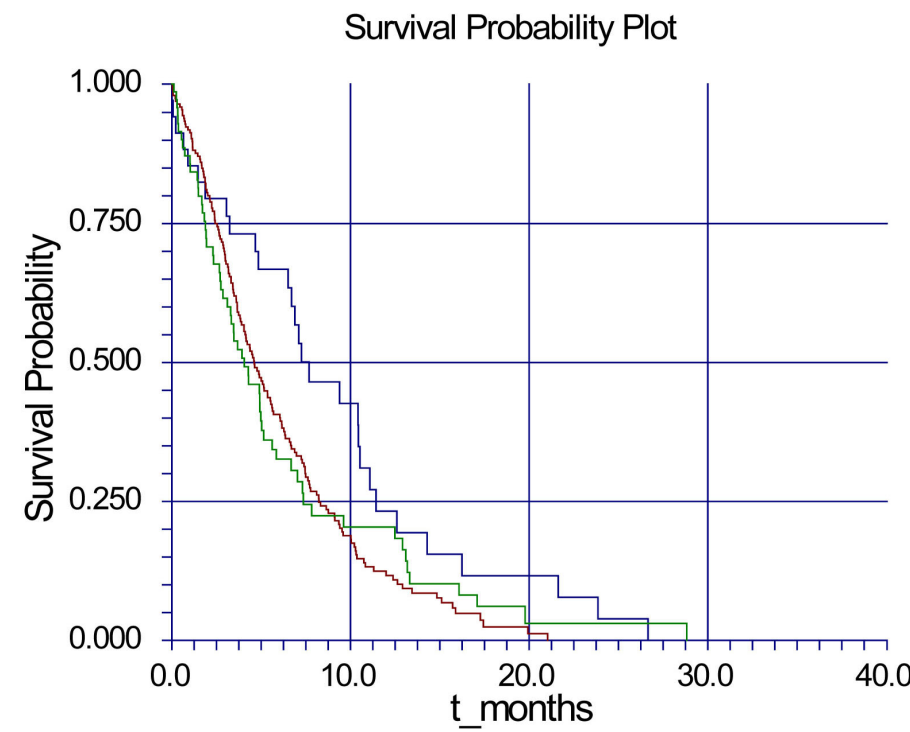

Figure 7. Kaplan Meier survival curves for survival probabilities of shaft/gearbox system in service boats.

Table 3. Cox Regression output: Risk factors associated with propulsion system failures.

\begin{tabular}{ccccc}
\hline Risk Factors & Hazard Ratio & Std. Err. & $\mathbf{z}$ & $\mathbf{P}>|\mathbf{z}|$ \\
\hline Insuff. Lub. Oil & 1.301 & 0.172 & 1.990 & 0.047 \\
Impact & 1.619 & 0.223 & 3.500 & 0.000 \\
Stress corrosion cracking & 2.328 & 0.405 & 4.860 & 0.000 \\
Model fitting information & & & & \\
No. of Obs. $=299$ & & & \\
Log-likelihood $=-1159.466$ & & & \\
LR Chi ${ }^{2}(3)=44.09$ & & & \\
Prob $>$ Chi $^{2}=0.0000$ & & &
\end{tabular}

Source: Author, data analysis. 
The significant risk factors affecting shaft and gearbox failures in service boats are according to coefficients of hazard ratio, stress corrosion cracking, impacts while underway at sea and insufficient lubrication oil in the gearbox or shaft bearings, see Table 3 . This finding is in agreement with existing studies on causes of metallurgical failures in propulsion shaft and gearbox systems. The outcome of this model could be used as a guide in design of robust maintenance programmes for companies operating fleet of service boats similar to the ones studied here.

\section{Summary/Conclusion}

In this study, we determined the frequency distribution of failures of shaft and gearbox components in supply, crew and tug boats. Specifically, it was found that each boat type exhibited particular frequency (time) and probability of failure. Shaft and gearboxes in Supply boats were found to have higher probability of failure than in crew boats and then followed by tug boats in this order. It was also found that probability of failure was higher within $0-10$ month's interval following boats' visits to dockyard for repairs. The Cox regression outputs showed that failure in shaft and gearbox marine propulsion system could be attributed to the following factors: insufficient lubrication, impacts related to environmental condition of water or and stress corrosion cracking in propulsion system's components. It is therefore proposed that these three factors could be controlled through proper design and strict adherence to maintenance schedule programme. The present research was based on a case study of a single dockyard. We assume here that a case study of this nature may limit generalizability of its findings. Thus, while we recognise this as a limitation, the methodology applied and findings are rather instructive and should provide a guide for expanded research on this theme in future studies involving multiple sampling units.

\section{Conflicts of Interest}

The authors declare no conflicts of interest regarding the publication of this paper.

\section{References}

[1] American Bureau of Shipping (ABS) (2019) Guidance Notes on Propulsion Shafting Alignment. American Bureau of Shipping, Houston.

[2] Ayyub, B.M., Beach, J.E., Sarkani, S. and Assakkaf, I.B. (2002) Risk Analysis and Management for Marine Systems. Naval Engineers Journal, 114, 181-206. https://doi.org/10.1111/j.1559-3584.2002.tb00130.x

[3] Tran, V.T., Nguyen, H.V., Ma, A.T., Doan, M.T. and Vo, T.C. (2016) Assessment of Marine Propulsion System Reliability Based on Fault Tree Analysis. International Journal of Transportation Engineering and Technology, 2, 55-61.

[4] Dong, C., Yuan, C., Liu, Z. and Yan, X. (2013) Marine Propulsion System Reliability Research Based on Fault Tree Analysis. Advanced Shipping and Ocean Engineering, 2, 27-33.

[5] Ashraf, K.N. (2017) Identification of the Actual Distribution of Demand for Spare 
Parts in Car Maintenance Service Stations. American Journal of Traffic and Transportation Engineering, 2, 26-31.

[6] Guan, L.H. (2013) A Study on Predictive Analytics Application to Ship Machinery Maintenance. Unpublished M.Sc. Thesis, Naval Postgraduate School, Monterey. http://hdl.handle.net/10945/37659

[7] Aksu, S. and Turan, O. (2006) Reliability and Availability of Pod Propulsion Systems Quality. Reliability Engineering International, 22, 41-58. https://doi.org/10.1002/qre.747

[8] Oberst, U. (2007) The Fast Fourier Transform. SIAM, Journal of Control \& Optimization, 46, 1-45. https://doi.org/10.1137/060658242

[9] Amidror, I. and Hersch, R. (2009) The Role of Fourier Theory and of Modulation in the Prediction of Visible Moiré Effects. Journal of Modern Optics, 56, 1103-1118. https://doi.org/10.1080/09500340902994140

[10] Zhang, Y. (2006) Order Bispectrum Based Gearbox Fault Diagnosis during Speed-Up Process. Proceedings of the 6 th World Congress on Intelligent Control and Automation, Dalian, 21-23 June 2006, 5526. https://wenku.baidu.com/view/b3081e12866fb84ae45c8d86.html

[11] Yue, Y. and Zhu, C. (2014) The Application and Research of Order Analysis in Gearbox Fault Diagnosis. Applied Mechanics and Materials, 635-637, 844-850. https://doi.org/10.4028/www.scientific.net/AMM.635-637.844

[12] Hongxia, P. and Liming, S. (2012) System Modelling and Application in Gearbox Fault Diagnosis Based on EMD and ARX Model. Applied Mechanics and Materials, 109, 532-536. https://doi.org/10.4028/www.scientific.net/AMM.109.532

[13] Li, Z., Yan, X., Yuan, C., Zhao, J. and Peng, Z. (2011) Fault Detection and Diagnosis of a Gearbox in Marine Propulsion Systems Using Bispectrum Analysis and Artificial Neural Networks. Journal of Marine Science Application, 10, 17-24. https://doi.org/10.1007/s11804-011-1036-7

[14] Lin, J. and Zuo, M.J. (2003) Gearbox Fault Diagnosis Using Adaptive Wavelet Filter. Mechanical Systems and Signal Processing, 17, 1259-1269. https://doi.org/10.1006/mssp.2002.1507

[15] Sharma, S.P. and Vishwakarma, Y. (2014) Application of Markov Process in Performance Analysis of Feeding System of Sugar Industry. Journal of Industrial Mathematics, 2014, Article ID: 593176. https://doi.org/10.1155/2014/593176

[16] Allison, P.D. (1995) Survival Analysis Using the SAS System: A Practical Guide. SAS Institute, Cary.

[17] Maciejewski, M.L., Diehr, P., Smith, M.A. and Hebert, P. (2002) Common Methodological Terms in Health Services Research and Their Symptoms. Medical Care, 40, 477-484. https://doi.org/10.1097/00005650-200206000-00005

[18] Nardi, A. and Schemper, M. (2003) Comparing Cox and Parametric Models in Clinical Studies. Statistics in Medicine, 22, 597-610. https://doi.org/10.1002/sim.1592

[19] Adeboye, N.O., Ajibode, I.A. and Aako, O.L. (2020) On the Survival Assessment of Asthmatic Patients Using Parametric and Semi-Parametric Survival Models. Occupational Diseases and Environmental Medicine, 8, 50-63. https://doi.org/10.4236/odem.2020.82004

[20] Gokovali, U., Bahar, O. and Kozak, M. (2007) Determinant of Length of Stay: A Practical Use of Survival Analysis. Tourism Management, 28, 736-746. https://doi.org/10.1016/j.tourman.2006.05.004 
[21] Kaplan, E.L. and Meier, P. (1958) Non Parametric Estimation from Incomplete Observations. Journal of the American Statistical Association, 53, 457-481. https://doi.org/10.1080/01621459.1958.10501452

[22] Cox, D.R. (1972) Regression Models and Life-Tables (with Discussion). Journal of the Royal Statistical Society: Series B, 34, 187-202.

https://doi.org/10.1111/j.2517-6161.1972.tb00899.x 
Appendix 1. Tabulation of Status of Shaft/Gearbox System

\begin{tabular}{cccc}
\hline Status & Freq. & Percent & Cum. \\
\hline 1 & 250 & 83.61 & 100 \\
0 & 49 & 16.39 & 16.39 \\
Total & 299 & 100 & \\
\hline
\end{tabular}

Key: 1: failed, 0: censored; Source: Authors; field work.

Appendix 2. Insufficient Lubrication oil Recorded as Cause of Failure

\begin{tabular}{cccc}
\hline Ins. Lubr. oil & Freq. & Percent & Cum. \\
\hline 1 & 174 & 58.19 & 100 \\
0 & 125 & 41.81 & 41.81 \\
Total & 299 & 100 & \\
\hline
\end{tabular}

Key: 1: yes, 0: no; Source: Authors; field work.

Appendix 3: Impact Recorded as Cause of Failure

\begin{tabular}{cccc}
\hline impact & Freq. & Percent & Cum. \\
\hline 1 & 194 & 64.88 & 100 \\
0 & 105 & 35.12 & 35.12 \\
Total & 299 & 100 & \\
\hline
\end{tabular}

Key: 1: yes, 0: no; Source: Authors; field work.

Appendix 4. Stress Corrosion Recorded as Cause of Failure

\begin{tabular}{cccc}
\hline corrosion & Freq. & Percent & Cum. \\
\hline 1 & 240 & 80.27 & 100 \\
0 & 59 & 19.73 & 19.73 \\
Total & 299 & 100 & \\
\hline
\end{tabular}

Key: 1: yes, 0: no; Source: Authors; field work. 